\title{
MUNDO RURAL Y MERCADOS: UNA ESTANCIA Y LAS FORMAS DE CIRCULACION MERCANTIL EN LA CAMPAÑA RIOPLATENSE TARDOCOLONIAL
}

\author{
POR
}

\author{
JORGE GELMAN
}

Si la riqueza en la sociedad colonial se producía esencialmente en la campaña (prod. agropecuaria, minera e incluso textil), y una parte sustancial de aquella era captada por el capital comercial, es fundamental estudiar de qué manera esto se realizaba.

Cuando la producción estaba en manos de pequeños productores, los métodos utilizados por el capital comercial parecen haber sido bastante similares en todos lados, desde las minas de plata potosinas en su período inicial, a la explotación de la yerba mate paraguaya o a la producción de textiles en distintos lugares de América: básicamente adelantar mercancías a precios inflados a los productores a cambio de comprarles luego la producción a precios bajos. Para poder hacer esto el capital mercantil se apoya en la "imperfección" de los mercados, la escasez de moneda y crédito, la falta de competencia para la venta y/o compra, y aun la coacción disimulada o abierta como en el caso extremo de los "repartos de mercancías» a las comunidades indígenas americanas (1).

Estos mecanismos parecen haber sido utilizados en el área que nos ocupa en la segunda mitad del siglo XVIII con los pequeños "labradores» que producen una parte importante del trigo que consume la ciudad de Buenos Aires, asi como otros productos

SIGLAS UTILIZADAS:

AGN: Archivo General de la Nación, Buenos Aires.

HAHR: Hispanic American Historiacal Review, Durham.

(1) Con respecto a los métodos de "rescatar" la plata en el Potosí inicial ver J. de Matienzo, Gobierno del Perí (1567), París-Lima, 1967, passim; para la yerba paraguayu, J. C. Garavagila, Mercado interno y economía colonial, Enlace-Grijalbo, México, 1983, cap. IV; para el caso de la relación del traficante con el campesino productor de algodón. C. Morin, Michoacan en la Nueva España del siglo XVIII, Crecimiento y desigualdad en una economía colonial, FCE, México, 1979, págs. 174 y sig. 
agrícolas y ganaderos. Según testigos de fines de la era colonial, en la época de la cosecha del trigo, en enero, la campaña era recorrida por una multitud de mercachifles que adelantaban productos e incluso plata a los labradores, recuperando luego sus respectivas cosechas a precios muy bajos (2).

Si esta parece ser una forma típica de relación del capital comercial con los pequeños productores, en el caso de las grandes unidades productivas la situación puede ser diferente, y justamente una de las claves de su eventual éxito pasaba por la adopción de parte de sus patrones, de los métodos propios del capital comercial, ligándose directamente con los grandes mercados para evitar caer en manos de los intermediarios y a su vez aplicando los mecanismos mercantiles en el interior de sus propiedades (3).

En este trabajo intentaremos estudiar estos problemas a través del caso de la llamada "estancia de las Vacas», gran propiedad rural situada en la Banda Oriental del Río de la Plata, cuyo propietario era la «Hermandad de la Caridad» de Buenos Aires (4).

Esta estancia situada al norte de Colonia, sobre el Río de la Plata, fue propiedad de los Jesuítas desde 1738 (5), y en 1778 pasó a manos de la Hermandad, institución formada por lo más granado de la élite de Buenos Aires, que la recibió como merced

(2) Ver el testimonio de P. A. GARcía, Diario de un viaje a Salinas Grandes, Eudeba, Buenos Aires, 1974 (primera edición 1836), págs. 26 y también las referencias indicadas por F. WEINBERG en su "Estudio Preliminar" a J. H. VIEYTES, Antecedentes económicos de la Revolución de Mayo, Raigal, Buenos Aires, 1956, págs. 93-94.

(3) Este tipo de situación es señalada por muchos trabajos que estudiaron empresas productivas en América colonical. Un ejemplo reciente sobre las minas de mercurio de Huancavelica en S. STERN, Los pueblos indígenas del Perú y el desafío de la conquista española, Huamanga hasta 1640, Alianza, Madrid, 1986, págs. 176-78: ver también MORIN, [1], págs. 226 y sig.

(4) Las fuentes sobre la estancia "de las Vacas", que incluyen cuentas completas para más de diez años de fines de siglo XVIII, la correspondencia de los administradores con la Hermandad, los informes de visitas realizadas a la misma con inventarios de ganados, inmuebles, etc., son sin duda las más ricas que se hayan encontrado hasta el presente sobre una estancia colonial rioplatense y han sido utilizadas parcialmente por J. BROWN en un pequeño capítulo de su libro $A$ socioeconomic History of Argentina, 1776-1860, Cambridge, Cambridge University Press, 1979, págs. 41-46, así como en el reciente artículo de este autor junto a R. Salvatore "Trade and Proletarianisation in Late colonial Banda Oriental: Evidence from the Estancia de las Vacas, 1791-1805", $H A H R, 67: 3,1987$, págs. 431459. La existencia de estas fuentes ya había sido señalada por otros autores como S. Socolow, The Merchants of BA, 1778-1810, Cambridge, C.U.P., 1978, pero hasta ahora no han sido explotadas en toda su riqueza.

(5) L. Sala de Touron, J. C. Rodríguez, N. DE la Torre, Evolución económica de la Banda Oriental, Ed. Pueblos Unidos, Montevideo, 1968, pág. 24. 
real para sostener financieramente una "casa de niñas huérfanas» y un hospital de mujeres (6).

Se trata sin duda de una gran estancia colonial, más típica de la banda oriental que de la occidental del Río de la Plata, con unas 40 leguas cuadradas de superficie, y con muy buenas rinconadas, ya que sus límites, además del Río de la Plata, son el arroyo de las Vacas por el norte y el río San Juan por el sur, que tienden a unirse hacia el fondo de la estancia donde se "cierra" la propiedad con los montes de Migueletes (7).

Las actividades de la estancia son muy variadas: explotación de caleras que son abandonadas para la época de la cual encontramos las cuentas, corte de leña y postes de sus montes boscosos, cultivo de trigo y eventualmente de otros cereales, huerta con árboles frutales y hortalizas, pero sin duda la actividad central era la ganadería y dentro de ella la explotación del vacuno, sobre todo para la extracción del cuero, sebo y grasa, aunque también encontramos cría de vacuno para el abasto de carne, eventualmente mular y excepcionalmente durante un año se intenta la salazón de carnes de manera sistemática, que luego se abandona.

CuAdro 1. VENTAS DE LA ESTANCIA, 1792-94

\begin{tabular}{|c|c|c|c|}
\hline PRODUCTO & & VALOR $\left(^{\circ}\right)$ & \% TOTAL \\
\hline \multirow{2}{*}{$\begin{array}{l}\text { Cueros (en Buenos Aires) } \\
\text { Leña (en estancia) }\end{array}$} & \multirow[b]{2}{*}{$1.423 \mathrm{p} 5 \mathrm{r}$} & $12.305 p$ & 66,46 \\
\hline & & $2.383 \mathrm{p} 5 \mathrm{r}$ & 12,87 \\
\hline $\begin{array}{l}\text { Leña (en Buenos Aires) } \\
\text { Mixto (en Buenos aires.A.) (grasa, sebo, char- } \\
\text { que, }\end{array}$ & $960 p$ & & \\
\hline leña, trigo, huerta, lenguas saladas) & & $2.201 \mathrm{p} 4 \mathrm{r}$ & 11,88 \\
\hline Carne (en estancia) & \multirow[b]{2}{*}{$249 p 7 r$} & $997 \mathrm{plr}$ & 5,38 \\
\hline Sebo, grasa, jabón (en Buenos Aires) & & $327 p 3 r$ & 1,76 \\
\hline Sebo, grasa, jabón (en estancia) & $77 p 4 r$ & & \\
\hline Cal (en estancia) & & $42 p 4 r$ & 0,23 \\
\hline Producción aún no vendida (**) & & $258 \mathrm{p} 6 \mathrm{r}$ & 1,39 \\
\hline TOTAL & & $18.515 \mathrm{p} 7 \mathrm{r}$ & 99,97 \\
\hline
\end{tabular}

Fuente: AGN, IX, 6.8.3. "cuenta general de cargo y data..."

$\therefore$ en pesos (p) y reales ( $r$ ) corrientes.

** a precios de la Banda Oriental.

(6) Ver el informe de "Dn. Martín Josef Altolaguirre al Sr. Virrey y al Sr. Obispo", 14 de enero de 1793, en AGN, IX, 6.8.2.

(7) Ver "Instrucciones que lleban los sres. Dn. F. Wright...", 30/5/1799, en AGN, IX, 6.8.5. 
CUADRO 2. EVOLUCION DEL STOCK GANADERO DE LA ESTANCIA, 1778-1799

\begin{tabular}{lrrrrrrrr}
\hline & 1778 & 1787 & 1790 & 1791 & 1792 & 1794 & 1796 & 1799 \\
\hline Vacuno rodeo & 16.249 & 11.453 & 13.314 & 15.611 & 16.008 & 16.239 & 25.476 & 32.826 \\
Vacuno alzado & 65.850 & 24.500 & 33.380 & 39.500 & 27.760 & 39.664 & $?$ & 32.316 \\
Tamberas & & & & & 112 & & & \\
Bueyes & 71 & 77 & 78 & 60 & 137 & 209 & 306 & 188 \\
Ovejas & 135 & 206 & 552 & 600 & 250 & 430 & & \\
Caballos sanos & & 6 & 218 & 69 & 530 & 230 & 912 & 448 \\
Caballos mancos & & & 337 & 574 & 530 & 248 & 191 \\
Caballos inservibles & 190 & 50 & 39 & 3 & & 203 & 83 & 59 \\
Caballos redomones & 595 & & 95 & 120 & 248 & 80 & 93 & 198 \\
Yeguas & 1.860 & 1.204 & 2.026 & 2.279 & 2.631 & 1.429 & 1.672 & 1.723 \\
Potros & 525 & 150 & 111 & 305 & 84 & 37 & 152 & 120 \\
Burros hechores & 690 & 780 & 700 & 1.000 & & 1 & & 13 \\
Cerdos & & 62 & 400 & 500 & & & & 40 \\
Mulas & 456 & & & & & 2 & & 40 \\
\hline
\end{tabular}

Fuentes: AGN, IX, 6.7.9., 6.8.1., 6.8.3. y 37.5.4. exp. 19.

En el Cuadro 1, donde se indica el resumen de las ventas de la estancia para los años 1792-94, se observa esta diversidad de actividades, pero también muy claramente el predominio absoluto del cuero vacuno en su relación con el mercado. Esto último es a su vez confirmado por la importancia del stock ganadero de la estancia, dentro del cual el vacuno ocupa el lugar central (Cuadro 2).

La estancia de las Vacas está plenamente vinculada al mercado, tanto en lo que respecta a la obtención de todo lo que necesita para su funcionamiento, como en cuanto al destino de su producción (8). Así por ejemplo para estos mismos años 92-94, lo único producido por la estancia y consumido en la misma son 45 ps 4 rls de jabón, 5.500 postes que son utilizados para levantar corrales y algunas carretas, un poco de grasa y sebo para el consumo de la "casa principal» y la Iglesia (aproximadamente 1 arroba de c/uno por mes) y por supuesto la carne de consumo del conjunto de los trabajadores de la estancia (9). Calculando el valor de estos productos a los precios a que los habría podido

(8) Esta característica de las estancias rioplatenses ya había sido señalada por HALPERIN al estudiar la estancia betlemita de Fontezuela, "Una estancia en la campaña de Buenos Aires, Fontezuela, 1753-1809", en E. Florfscano (comp.) Haciendas, Latifundios y Plantaciones en América Latina, México, Siglo XXI, 1975, pág. 461.

(9) Las fuentes para esto son las mismas del Cuadro 1. 
vender la estancia, llegamos a la cifra de 3.108 ps (10), es decir que de la producción total de la estancia en ese período, apenas un $14,4 \%$ no estaría destinado al mercado, sino al consumo o autosuficiencia de la explotación (11). Y sin duda que éste es un cálculo bastante arbitrario, ya que los costos de producción de dichos productos (los no vendidos), se acercan sensiblemente a 0 , en particular los de la carne que es el principal rubro, ya que las reses faenadas lo son sobre todo para extraerles el cuero, sebo, grasa y lengua que sí son vendidos, quedando a la estancia la alternativa de dejar pudrir la carne (cosa que ocurría de cualquier manera con una parte de la misma), dársela como ración a los empleados o si no venderla, lo que no siempre era posible dada la pequeñez de los mercados locales consumidores de carne, fuera de la ciudad de Buenos Aires a la cual la estancia nunca le vende este alimento.

Sea como sea, queda claro que la estancia produce casi todo para el mercado y de la misma manera obtiene en el mercado casi todo lo que necesita para funcionar.

Aunque más adelante nos detendremos en detalle en los gastos de la estancia, queremos señalar que ya sea la plata o productos que se paga como salarios, las raciones y géneros para el mantenimiento de los esclavos, como las herramientas y otros insumos, todo se obtiene a través del mercado, a excepción de esa misma carne que ya señalamos al hablar de la producción.

Estamos entonces frente a una situación bastante diferente de la de algunas haciendas que conocemos del Perú o de Nueva España en donde la estrategia de las mismas parece ser lograr un máximo grado de autosuficiencia que les permita reducir la vinculación con el mercado a la venta de uno o dos productos, limitando en la medida de lo posible toda compra. Esto como modo de reducir los riesgos de la empresa frente a las debilidades y fluctuaciones de los mercados consumidores de sus productos. Incluso una situación similar la encontramos dirigiéndonos sólo unas centenas de kilómetros tierra adentro en la propia región

(10) Llegamos a esos 3.108 ps sumando: 45 ps de jabón +687 ps de postes (son 5.500 que se venden a un real c/uno) +36 ps de grasa y sebo (son 36 arrobas de grasa y otras tantas de sebo consumidas en 3 años a 4 rls c/una) + 2.340 ps por otras tantas reses (calculando a 780 reses consumidas por año como lo indíca de manera estimativa un cálculo de gastos e ingresos de la estancia en 1790, "Estado que manifiestan las pensiones...", 7/6/1790, AGN, IX, 6.7.9.).

(11) Sumando la producción vendida por la estancia en esos años (18.515 ps $7 \mathrm{rls}$, ver Cuadro 1) más el valor hipotético de esta producción consumida allí (3.108 ps), llegamos a la cifra de 21.623 ps, con lo cual la producción no mercantil de la estancia llegaría a un 14,4\% del total. 
rioplatense, como lo señaló Cushner para las haciendas jesuíticas de Córdoba, que trataban de producir el máximo de insumos para el pago de sus peones y suministro de sus esclavos (12).

La situación peculiar de las estancias rioplatenses ha sido explicada por la relativa escasez y carestía de la mano de obra local (tanto esclava como asalariada) (13), pero creemos necesario agregarle por lo menos dos factores más: 1) las características de los mercados a los cuales éstas destinaban su producción y 2) las características de la relación entre la estancia y la mano de obra.

En primer lugar el grado de mercantilización de la economía regional parece haber sido superior al de otras regiones, ya que no solo los habitantes de la ciudad compran casi todo lo que consumen en el mercado, sino que incluso los habitantes de la campaña en parte lo hacen (recordamos que parecería una de las pocas regiones en las cuales la mujer campesina no produce tejidos para su familia, amén de las necesidades de "vicios» [yerba, vino, etc.] (14). Además la producción de la estancia, como se ve claramente en el caso de las Vacas (Cuadro 1), está destinada a varios mercados complementarios o alternativos (los cueros se venden esencialmente en Buenos Aires para Europa, pero en parte se pueden derivar hacia el Brasil, la leña se puede vender localmente en la Banda Oriental, en Buenos Aires y aún en el resto del litoral donde el flete barato permite obtener una utilidad, el sebo y la grasa otro tanto, etc.).

La diversificación de la producción y de los mercados a los que se destina, es una política consciente de la estancia de las

(12) Para el Perú señalan muy claramente este tipo de actitud empresarial los estudios de Polo y LABORDA "Pachachaca, una hacienda feudal, autoabastecimiento y comercialización", en TORD y LAzo (comp.) Hacienda, Comercio, Fiscalidad y Luchas Sociales (Perú colonial), BPHES, Lima, 1981, págs. 9-53, y L. M. GLAVE y M. I. REMY, Estructura agraria y vida rural en una región andina. Ollantaytambo entre los siglos XVI-XIX, Cusco, C.B. de las Casas, 1983, págs. 359 y sig. En el caso de Nueva España la situación parece más compleja y diversificada (será por la existencia de muchos más trabajos sobre haciendas que para el Perú colonial?), pero por ejemplo H. Konrad, A jesuit Hacienda in Colonial Mexico. Santa Lucia, 1576-1767, Stanford, Stanford University Press, 1980, págs. 211-12 y 238, señala claramente que la estrategia de los jesuítas en el complejo de haciendas de Sta. Lucía del México Central, es minimizar las compras externas, tratando de cubrir el máximo de gastos con producción propia. El caso de Córdoba, ver $\mathrm{N}$. CUSHNER, Jesuit Ranches and the Agrarian Development of Colonial Argentina, 1650-1767, Albany, State University of New York Press, 1983, pág. 72.

(13) Halperin, [8], pág. 460.

(14) Ver J. C. Garavacilia, "Los textiles de la tierra en el contexto colonial rioplatense: Una revolución industrial fallida?", en Anuario IEHS, Tandil, Argentina, N1, 1986, págs. 45-88. 
Vacas. En 1790 y 91 la Hermandad realiza sendas visitas de inspección a la estancia, de resultas de lo cual se elaboran instrucciones y planes para el buen funcionamiento y rendimiento de la misma. En ambas "instrucciones», partiendo de la base de que el eje de las ventas de la estancia son los cueros vacunos, se recomienda aprovechar al máximo los otros recursos de ese ganado (grasa, sebo, lenguas saladas, carne) y a su vez desarrollar otras producciones como la de la madera, cereales, mulas, cal, etc. Sobre todo se cifran muchas expectativas en desarrollar la explotación maderera destinada a mercados locales, a un nivel que sus beneficios permitan sufragar el conjunto de los gastos de la estancia, dejando como utilidad neta todos los ingresos restantes (15). Si bien esta pretensión nunca se cumplirá en la estancia de las Vacas, constatamos en el Cuadro 1 la diversificación de las ventas de la estancia y la importancia de la madera dentro de ello, lo cual demuestra la preocupación de sus dueños por disminuir los riesgos que producían los altibajos en el mercado de su principal producto vendible, el cuero.

De cualquier manera esto no impide que esos mercados sean débiles y muy fluctuantes, como lo es en ésta época el mercado europeo para los cueros, producto de las sucesivas guerras que interrumpen el tráfico.

Y entonces aquí interviene el otro factor que permite la mercantilización de la producción de la estancia: ésta puede adecuarse a las alternativas de los mercados a los cuales destina su producción, a través de la fluida relación contractual con sus empleados.

Si algo surge con claridad de los todavía escasos estudios de estancias rioplatenses de fines de la era colonial, es que la mayor parte de los trabajadores no tienen ningún tipo de fijación a las mismas, ya sea establecida de manera contractual, a través del endeudamiento o de otros mecanismos, sino que disponen de una amplia movilidad (16). Esto es confirmado por el movimiento

(15) Todo esto en AGN, IX, 6.8.1. "Instrucciones para el ramo de la leña...", 31/7/1791, "Plan..." 31/7/1791 y "Pliego de prevenciones con 30 artículos..." 31/7/1791; y AGN, IX, 6.7.9., "Instrucciones que forman Dn. Martín Josef Altolaguirre..." 4/6/1790 y "Estado que manifiesta las pensiones..." 7/6/1790.

(16) Ver Halperin, [8]; J. Brown y R. Salvatore, [4]: S. Amaral "Rural production and labor in late colonial Buenos Aires"; C. MAYo "Sobre peones, vagos y malentretenidos: el dilema de la economía rural rioplatense durante la época colonial", en Anuario IEHS, 2, 1987, Tandil, "Estancia y peonaje en la región pampeana en la segunda mitad del siglo XVIII", Desarrollo Económico, 92, 1984, págs. 609-616 y "Convento, economía y sociedad en el Río de la Plata", Ph D. Diss., University of California, Los Angeles, 1984. 
de la mano de obra de la estancia de las Vacas, donde los peones entran y salen constantemente del empleo, ya sea por voluntad propia o a veces por la de la estancia.

La necesidad de la estancia de adaptar la contratación de trabajadores (y por lo tanto los gastos) a los vaivenes de los mercados, así como a las fluctuaciones estacionales del trabajo agropecuario, explica también en parte por qué aquella no puede reemplazar los peones por esclavos de manera total, a pesar de su mayor baratura relativa, ya que esto implicaría que tanto en los momentos de baja demanda laboral estacional de cada año, como en los años en que la estancia necesita reducir la producción, se encontraría con una gran masa de mano de obra ociosa, cuyos gastos igual debe sufragar (17). Y quizás también por lo mismo, en aquellas estancias como las jesuitas (o en menor medida las betlemitas), donde se tiende a reemplazar al máximo posible la mano de obra asalariada por esclava, también se tiende a diversificar al máximo las actividades agropecuarias y artesanales, como modo de reducir la incidencia de las fluctuaciones estacionales del trabajo, así como de aumentar las alternativas de mercados y eventualmente lograr un mayor grado de autosuficiencia (18).

En el caso de la estancia de las Vacas, tenemos entonces una gran propiedad altamente mercantilizada. Como veremos, a diferencia de lo que sucede con los pequeños productores, ésta va a tratar de emplear a su favor los mecanismos propios del capital comercial.

\section{LOS MECANISMOS MERCANTILES DE LA ESTANCIA Y SU RENTABILIDAD}

Lo primero que hace la estancia para mejorar sus ingresos es tratar de llegar sin intermediarios a los mercados a los cuales se dirige su producción. Esto lo logra con bastante éxito con los productos menores como la carne o la madera y en el caso del cuero, su principal producto, si bien la estancia de las Vacas no

(17) Sobre este tema del movimiento de la mano de obra no nos detendremos aqui, lo hemos desarrollado en detalle en el trabajo "Sobre esclavos, peones, gauchos y campesinos. El trabajo y los trabajadores en una estancia colonial rioplatense", a publicarse próximamente en un libro colectivo. El cálculo sobre la mayor baratura relativa del esclavo sobre el peón, en esta región y en esta época, cuando realiza tareas a lo largo del año, se puede ver en AMARAL, [16].

(18) Ver los casos analizados por Cushner, [12], C. MAYo, [16], y HaLPERIN, 
se ocupa de su comercialización a Europa que es sin duda el que más ganancias permite obtener, trata de colocarlos al mejor precio posible en Buenos Aires que es el punto intermedio anterior. De la misma manera todos los insumos que la estancia necesita trata de comprarlos en el mercado regional donde más baratos se consiguen, que normalmente es la ciudad de Buenos Aires (por lo menos cuando se trata de mercancías europeas).

Si esto mejora la posición de la estancia frente al mercado, sin embargo no le garantiza una alta rentabilidad, ya que los factores determinantes de la misma, en particular de sus ingresos, dependen de fluctuaciones que escapan totalmente a su control (como es el caso de las bruscas caídas en la demanda [y en el precio!] de los cueros por las guerras que interrumpen el tráfico atlántico).

En el caso de nuestra estancia esto está agravado por otro factor.

Es lógico suponer que una estancia cuyo producto está destinado a la acumulación, va a reaccionar de manera positiva a los estímulos del mercado. Con esto queremos decir que cuando aumenta la demanda (y los precios) para sus productos va a tender a aumentar en la medida de lo posible su producción y viceversa en años malos, tendiendo a acumular el stock ganadero para mejores épocas.

Muy diferente debe haber sido la reacción de un pequeño productor, cuyas ventas en el mercado estaban destinadas a satisfacer necesidades básicas de subsistencia: ante una baja en el precio de sus productos, debían tender a aumentar la producción y venta para lograr mantener así su nivel mínimo de consumo. En el caso de la estancia que estamos analizando, las reacciones a los estímulos del mercado, parecen haber seguido en ciertas ocasiones los patrones de ese pequeño productor y no tanto los de un "estanciero-capitalista».

Un claro ejemplo de esto es lo que hace la estancia en 1797, un año después de iniciada la guerra europea, que interrumpe el comercio atlántico, provocando la caída del precio del cuero en Buenos Aires, que se abarrota en sus barracas.

Sabemos por un lado que las exportaciones americanas y rioplatenses a España caen abruptamente en 1796 y los años siguientes (19), y correspondientemente también caen los precios

(19) Ver J. Fisher "The Imperial Response to Free Trade: Spanish Imports from Spanish America, 1778-1786", JLAS, 17:1, 1985, págs. 35-78 y J. CuENCA ESTEBAN "Statistics of 'Spain's colonical Trade, 1792-1820", HAHR, 61:3, 1981, págs. 384-428. 
del cuero como se confirma por las propias ventas de la estancia de las Vacas. Así mientras en 1790 que es un buen año de exportaciones de cueros a España, la estancia los vende en Buenos Aires a un promedio de 1,3 ps por unidad, en 1797 solo llega ese promedio a 0,93 ps (20).

El administrador de la estancia lejos de bajar la producción ante la coyuntura desfavorable, recibe una orden de la Hermandad para que aumente el faenamiento de ganado y las remesas de cueros, porque tienen que cubrir muchos gastos, y todo esto como lo dice la carta del Hermano mayor “...aunqe. el cuero tenga poco balor..." (21).

El resultado de esta política, comparando nuevamente 1790 con 1797, es que en aquel año la Hermandad recibe de la estancia 4.687 cueros que producen un ingreso de unos 6.100 ps y en 1797 se reciben 9.200 cueros que producen unos 8.500 ps aproximadamente (22).

Es decir que duplicando la producción en 1797, los ingresos solo aumentan en cerca del 40\%, con lo cual la rentabilidad cae.

Esta reacción "poco capitalista» a los estímulos del mercado, se debe sin duda a que la estancia de las Vacas pertenece a la Hermandad de la Caridad de Buenos Aires, y su producto está destinado básicamente, no a la acumulación, sino al mantenimiento de un colegio de huérfanas y un hospital de mujeres, que de otra manera no se pueden mantener, ya que los "capitalistas» miembros de la Hermandad no están dispuestos a sufragar estos gastos a su propia costa (23).

Este tipo de reacción ante los estímulos del mercado, por otía parte, no parece una excepción, habiendo sido señalado por otros autores que estudiaron las haciendas jesuíticas, por ejemplo, cuyo producto también estaba destinado en gran medida a sufragar gastos fijos (24).

Si los factores determinantes de los ingresos de la estancia por la venta de su producción, escapan bastante de sus manos (en particular la evolución de sus precios), lo que la estancia va a

(20) Las fuentes para esto en AGN, XIII, 47.6.9., "Libro de Thesoreria... de la Hermd. de la Sta. Caridad...".

(21) Carta del 8/7/1797, AGN, IX, 6.8.4.

(22) Cf. nota 20.

(23) No solo esto es así, sino que algunos miembros de la Hermandad trataron de sacar provecho propio a costa de esta estancia, como veremos más adelante.

(24) Ver Cushner, N., Lords of the Land: Sugar, Wine and Jesuit Estates of Coastal Peru, 1600-1767, New York, 1980, págs. 122-123. 
tratar de regular y reducir son los gastos de la explotación para mejorar su rentabilidad.

Veamos primero como es la estructura de gastos de la estancia de las Vacas, para algunos años.

CUADRO 3. INCIDENCIA DE LOS GASTOS SALARIALES EN LOS GASTOS TOTALES CORRIENTES DE LA ESTANCIA DE LAS VACAS (en pesos corrientes)

\begin{tabular}{lcrrrrr}
\hline & \multicolumn{2}{c}{$1792-94$} & \multicolumn{2}{c}{1796} & \multicolumn{2}{c}{$1805(4)$} \\
& MONTO & $\%$ & MONTO & $\%$ & MONTO & $\%$ \\
\hline Salarios & 9.6294 & 65,7 & 3.8833 & 80,8 & 2.0883 & 65,2 \\
Esclavos (1) & 2.2614 & 15,5 & 2974 & 6,2 & 335 & 10,5 \\
Fletes (2) & 2.270 & 15,5 & 274 & 0,6 & 451 & 14,1 \\
Otros (3) & 4934 & 3,3 & 5946 & 12,4 & 3284 & 10,2 \\
TOTAL & 14.6544 & 100 & 4.8031 & 100 & 3.2027 & 100 \\
\hline
\end{tabular}

Fuentes: AGN, IX, 6.8.3., 6.8.7., 37.5.4. (exp. 17) y AGN, XIII, 47.6.9.

(1) El gasto por esclavos incluye ropa y raciones, aunque una parte de estas últimas en los casos de 1796 y 1805 aparece mezclada en los "otros" gastos. El gasto por esclavos de 1792-94 aparece muy inflado porque esta cifra incluye la compra de 5 "bozales" en esos años.

(2) Como se puede observar por las cifras, en el gasto por fletes en 1796 no figuran los realizados entre la estancia y Buenos Aires, que son siempre los más elevados.

(3) En este rubro aparecen gastos en la reparación o compra de algunas herramientas o animales destinados al trabajo (bueyes, caballos), arreglos de instalaciones, así como gastos para la iglesia (incieso, cera) y otros que podríamos llamar de "gestión" (viajes del administrador a Colonia, papel, libros de cuenta, etc.). En los casos de 1796 y 1805 aparecen allí incluidos algunos gastos para raciones de esclavos que no hemos podido desglosar de otros gastos "de la casa".

(4) Los gastos de este año son hasta el 26/11, ya que por cambio del administrador en esa fecha, allí termina la cuenta que nos ha llegado. Hemos suprimido de los gastos de este año los debidos a la entrega de la estancia al nuevo administrador.

Como se puede observar en el Cuadro 3, en los 5 años que allí se analizan, los costos en mano de obra ocupan cerca del $80 \%$ de los gastos totales corrientes de la explotación. El hecho de que sea un poco mayor en 1796 se debe sin duda a que en las cuentas de ese año no figuran los gastos de fletes pagados por la Hermandad en Buenos Aires, lo que hace aumentar proporcionalmente los otros gastos.

Este peso abrumador de los costos de mano de obra (y esen- 


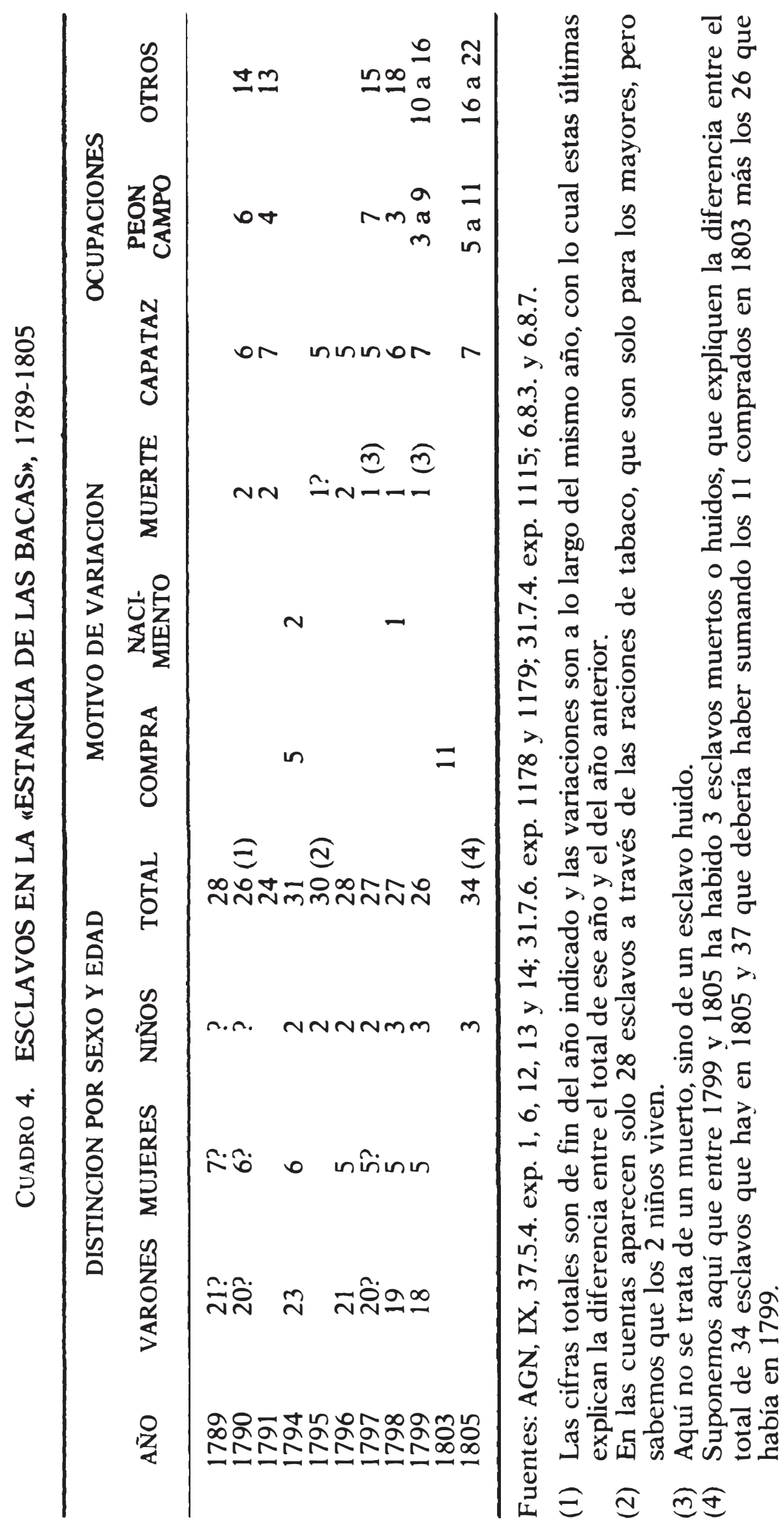


cialmente salariales) es muy comparable al de otras estancias rioplatenses que se han estudiado, así como de otras regiones americanas (25).

Siendo ésta la situación, plantearse reducir los gastos de explotación equivalía casi a reducir los gastos en mano de obra. Esto se hubiera podido lograr de varias maneras en teoría, pero en la práctica las posibilidades eran limitadas.

Una de estas alternativas sería reemplazar progresivamente la mano de obra asalariada por esclava, que resultaba más barata en la medida que tuviera una vida útil prolongada y se la utilizara en tareas permanentes a lo largo del año (26).

Consciente de ello la Hermandad se planteó en varias oportunidades la necesidad de adquirir más esclavos jóvenes «...pa. ahorrar igual número de peones...» (27).

Sin embargo como se puede observar en el Cuadro 4, desde 1789 hasta 1805 la estancia de las Vacas solo compró esclavos en dos oportunidades: 5 en 1794 y 11 en 1803.

En el primer caso el Hermano Mayor de la Caridad explica la decisión por las bajas utilidades de la estancia «...por el excesivo número de peones que continuamente se conchaban pa. la custodia de los ganados por existir alli pocos esclavos..." (28).

Sin embargo esta cantidad nueva de esclavos no soluciona mucho, ya que comparando los esclavos empleados en las faenas de campo (Cuadro 4) con los peones conchabados en esos años (Cuadro 5), los primeros son aún una pequeña proporción de la mano de obra total.

Además el objetivo central de la Hermandad con estos esclavos es sobre todo formar al personal de confianza y conocedor de las actividades del campo, capaces de ejercer los cargos de capataces de los 8 a 10 puestos que tiene la estancia, mientras que lo esencial de los peones de campo van a seguir siendo

(25) Ver S. Amaral, [16], pág. 17, donde el costo de mano de obra es el 81,4\% del total gastado. POLO Y LaBORDA, [12], págs. 37; Glave y REMY, [12], pág. 364; Morin, [1], pág. 220; E. VAN YoUnG, Hacienda and Market in Eighteenth Cénturv Mexico: the rural economy of the Guadalajara region, 1675-1820, Berkeley, University of California Press, 1981, pág. 247.

(26) C. nota 17. De hecho algunas estancias como las jesuitas o betlemitas adoptaron el criterio de reemplazar cada vez más los peones por esclavos (HALPERIN, [8], CuSHNER [24] y C. MAYO, [16], pero por razones que desarrollaremos luego esto no era posible para la mayoría de las grandes explotaciones laicas.

(27) Así se lo plantearon por ejemplo, luego de una visita a la estancia en 1791 "Pliego de prevenciones...", 31/7/1791, AGN, IX, 6.8.1.

(28) Carta del Hermano Mayor 3/6/1794, AGN, IX, 6.8.3. 


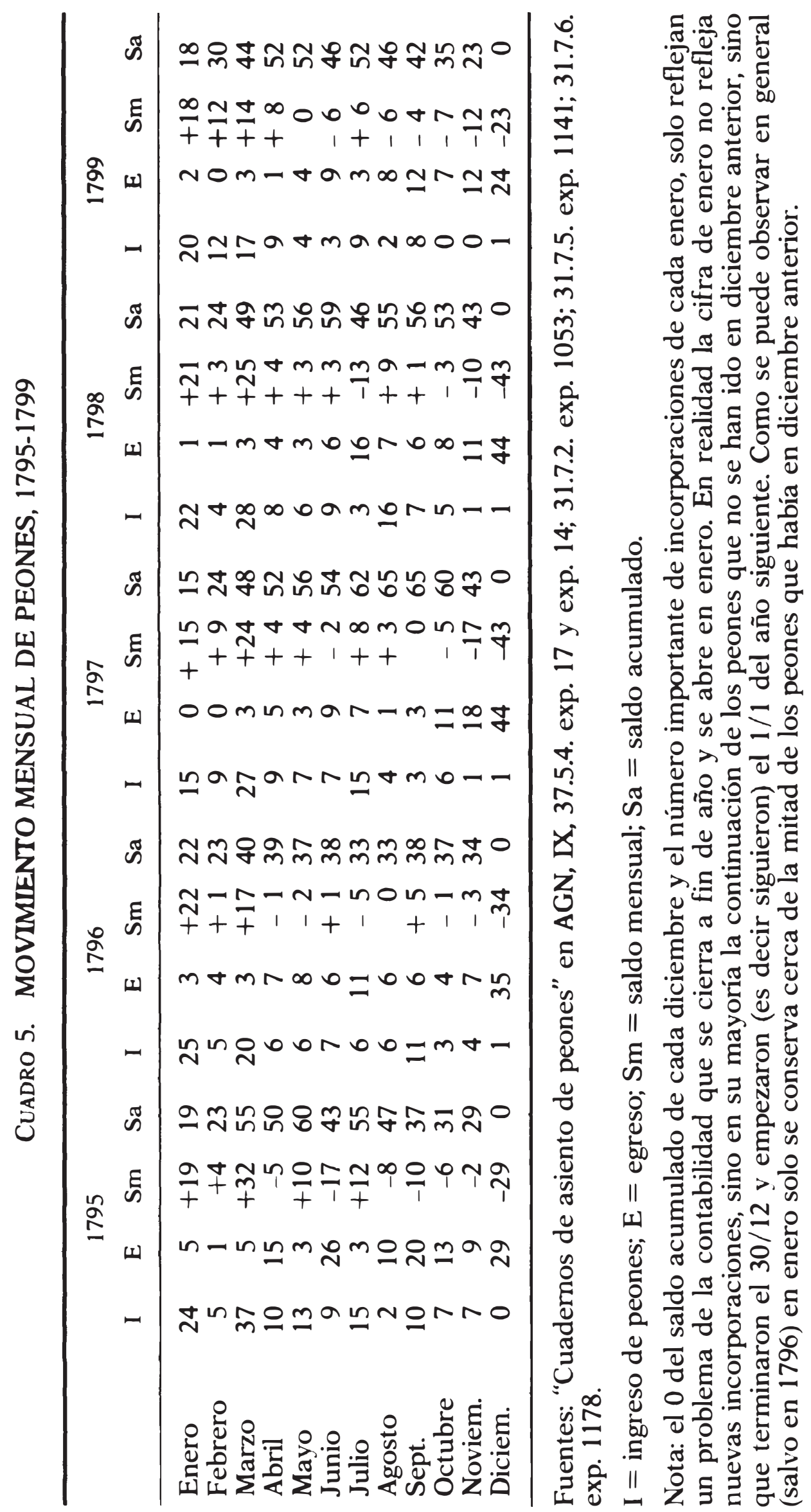


asalariados. Solo en 1803, el número de esclavos adquiridos indica una voluntad real de reemplazar algunos peones de campo.

Cuáles son las posibles razones de no haber usado más decididamente este expediente para "ahorrar gastos»?

En primer lugar las características muy fluctuantes de las labores agropecuarias de la estancia. Como se puede observar en el Cuadro 5 hay una estacionalidad bastante marcada en las tareas dentro de cada año (29) y por lo tanto no se pueden adquirir los esclavos necesarios para cubrir todas las tareas en el momento de máxima demanda para que luego esa mano de obra quede ociosa. Además de esta fluctuación estacional de la demanda laboral, hay una fluctuación muy marcada entre los diversos años.

Si observamos el Cuadro 5, los mínimos de peones de cada año varían de 15 en 1797 a 22 en 1796 y los máximos de 33 en 1796 a 65 en 1797 (30).

Por lo tanto para decidir invertir en mano de obra esclava, la estancia debería buscar algo así como el mínimo común denominador de sus necesidades laborales, teniendo en cuenta la fluctuación estacional y las cíclicas. Si la primera de éstas es más o menos previsible para una determinada explotación, la segunda es casi totalmente imprevisible y esto agrega un factor de riesgo muy importante a la hora de decidir una inversión como la compra de esclavos. A su vez hay otros factores de riesgo a considerar, que solo existen para la mano de obra esclava y que son esencialmente la posibilidad de muerte prematura del esclavo, su enfermedad o su huída (31).

Y hasta aquí solo hablamos del factor conveniencia ante la alternativa de comprar esclavos o contratar peones libres. También es necesario considerar otro factor decisivo: la posibilidad de hacer una u otra. Sobre todo la posibilidad concreta para el propietario de disponer del dinero o crédito suficiente para realizar la compra de esclavos. Y en esto quizás haya una diferencia importante entre las estancias de los religiosos (y en especial jesuitas) y de la mayoría de los propietarios laicos: los primeros

(29) Esto es confirmado en el caso de la estancia analizada por S. AmARAL, [16], donde incluso la estacionalidad es más marcada que en las Vacas.

(30) HaLPERín que estudió las cuentas de Fontezuela para unos 50 años seguidos, ha encontrado que tanto los gastos como los ingresos de la misma son extremadamente variables a lo largo de los años, art. cit., págs. 450-51.

(31) Cushner nos da el ejemplo de los jesuitas de Córdoba, que teniendo 460 esclavos en 1710, pierden 325 en la epidemia de 1718, [12], pág. 102. En nuestra estancia encontramos por lo menos tres casos de esclavos huidos. 
disponían de más dinero contante y sonante o de acceso a crédito que los segundos, así como los segundos, en el caso de los más ricos, disponian de otras alternativas de inversión más especulativas (comercio, etc.) que los primeros preferían no utilizar (32).

Otra posibilidad para reducir los costos es la de reducir el número de trabajadores necesarios para las mismas tareas, es decir aumentar la productividad del trabajador que en este caso concreto significa esencialmente mejorar la relación peón-cabezas de ganado de rodeo.

Es muy conocido el cálculo de F. de Azara hecho en un escrito de 1801, de que solo se necesitaban 11 trabajadores (1 capataz y 10 peones) para mantener un rodeo de 10.000 vacunos en la campaña rioplatense, argumento que utilizaba para demostrar los bajos costos laborales de la ganadería a diferencia de la agricultura (33).

Sin embargo en nuestra estancia las cosas no parecen ser tan ideales. Según las instrucciones hechas después de la visita de 1790 (34), se necesitaba como personal permanente para cuidar los rodeos, 8 capataces (uno por cada puesto) y 22 peones. $\mathrm{Si}$ comparamos esta cifra con el stock de ganado manso de ese año (Cuadro 2), encontramos una relación de cerca de 23 personas para 10.000 animales, es decir más del doble de las señaladas por Azara!

Y esta aún es la propuesta del visitador de la Hermandad para mejorar las cosas en la estancia. En los hechos la relación peones-cabezas de ganado parece haber sido peor para la rentabilidad de la estancia. A mediados de la década del 90 la Hermandad comienza a investigar las causas de sus bajas utilidades y el encargado de recoger las opiniones, Tomás Antonio Romero (a su vez estanciero), sostiene que el problema reside justamente en la gran cantidad de. peones utilizados para custodiar los rodeos. Que esto último a su vez se debe al exceso de puestos y rodeos y a la mala distribución del ganado en los mismos, habiendo algu-

(32) Obviamente un gran comerciante disponía del dinero o crédito para adquirir esclavos, pero lo esencial de sus inversiones se dirigían siempre a reiniciar el ciclo de sus actividades comerciales (en todo caso comprar esclavos para luego venderlos). Es llamativo por otra parte que cuando la estancia hace su mayor esfuerzo de inversión en 1803 para la compra de 11 esclavos, es también porque ha conseguido un contrato ventajoso, por el cual los va a pagar con carne-tasajo producido por la estancia en los 5 meses siguientes. Ver carta del H. Mayor 18/2/1803. AGN, IX, 6.8.7.

(33) Memoria sobre el estado rural del Río de la Plata y otros informes, BA, Bajel, 1943, págs. 7-8.

(34) Cf. nota 15. 
nos rodeos de apenas 800 cabezas que requieren casi de tanto personal como uno de 4 a 5.000. Dice que después de haber consultado "con estancieros especulativos" coincidieron que lo "regular" es que cada puesto tenga 6.000 cabezas, con lo cual en "Las Vacas» hay 5 rodeos de más y 14 peones permanentes también en exceso, y uésta es la verdadera causa del ningún producto de esa Hacienda" (35).

Sin embargo lo que este informe no considera, como no consideró F. de Azara, es que para ahorrar peones a través del mantenimiento de rodeos de 5 a 6.000 animales cada uno, se requieren condiciones ideales, probablemente imposibles de lograr, en el marco de las condiciones técnicas y ecológicas dadas de esa región y época (sin alambrados ni aguadas artificiales, se hubiera requerido de suficiente tierra en un lugar apto, con sus aguadas naturales, con sus rinconadas, sin ganado alzado a sus alrededores, etc.).

De hecho la estancia de las Vacas, a pesar de las recomendaciones de los estancieros "especulativos", no parece haber modificado de manera importante la relación hombres-vacas, salvo en el intento a fines de esa década de reunir todo el ganado alzado en un solo lugar (la "horqueta de San Juan»), para además de irlo domesticando o faenando, impedir que levante al manso, con su consecuente mayor consumo de trabajo.

Dado entonces que a la estancia no le conviene o no puede reemplazar los peones por esclavos, ni reducir los trabajadores necesarios para las mismas tareas, no parece quedar otra vía para reducir los gastos (manteniendo el nivel de empleo por tarea dada) que reducir los salarios de los peones empleados.

Reducir los salarios nominales de los peones, no parece haber sido posible para una determinada estancia rioplatense de esta época y la razón de ello es bastante obvia: con el sistema de contratación de empleados que hemos visto existía en la región, con una amplia libertad de ingreso y egreso tanto en el mercado laboral en general, como al conchabo en una u otra explotación, una estancia no podía reducir sus salarios, sin que esto implicara quedarse sin peones. Esto no quiere decir que los salarios fueran siempre los mismos en todas las explotaciones, ni en todo momento, influyendo en esto el área, la coyuntura, la época del año, la tarea a realizar, etc. Pero en todo caso la evolución de los salarios en determinadas condiciones en una explotación, parece

(35) Carta de T.A. Romero 8/7/96 y 23/11/97, en AGN, IX, 6.8.4. 
haber sido parecida a la evolución en otras explotaciones del área, en condiciones similares.

En la estancia de las Vacas, en el período que estamos estudiando, los salarios de los peones ganaderos en los puestos giraron siempre alrededor de 7 ps mensuales, incluso encontramos algunas cuentas aisladas de la década del 80 (1781-82 y 1785-86) en que también la mayoría de los salarios son de 7 ps (36). Por supuesto con algunas leves modificaciones, en particular una tendencia desde mediados de la década del 90 hasta fines de la misma, de aumentar la cantidad de peones a quienes se paga 8 ps por mes. Pero esta tendencia no parece el producto de una política particular de la Hermandad, sino más bien la adaptación a una tendencia general de los salarios en esa zona en esos años, amén del caso particular de 1797 que es el año de mayor demanda laboral de la década en la estancia de las Vacas, donde probablemente para conseguir fácilmente los peones, hayan aumentado los salarios un poco por encima de sus vecinos estancieros.

Que la determinación del nivel del salario nominal, sigue las condiciones del mercado de trabajo local, nos lo confirma el administrador de la estancia en una carta a la Hermandad en 1795:

...los peones que no doman en esta estancia... qe. solo ganan 6 ps por mes a excesion de los capataces, y los restantes de campo a 7 ps, y el que no doma potros monta en redomones que son peores algunos qe. los mismos potros: y están en práctica por esta Banda a el domador se le paga 8 ps y los mas peones se me quieren salir por este motivo de no hallarse gustosos con los $7(37)$.

Si entonces, como vemos, resulta difícil para un propietario bajar el salario nominal directamente, la estancia de las Vacas va a intentar hacerlo de manera indirecta, utilizando un mecanismo muy conocido en América colonial: aumentar en la medida de lo posible el porcentaje de salario pagado en productos.

Las fuentes de la estancia de las Vacas nos permiten analizar

(36) Estas últimas cuentas en AGN, CaSavalle, leg. 17, "Carta cuenta..." $21 / 9 / 1781$ a $31 / 3 / 1782$ y AGN, IX, 6.7.9. "Cuenta por menor..." 30/9/1785 a $31 / 3 / 1786$ y $31 / 3 / 1786$ al 30/9/1786. En cuanto a la evolución salarial de la década del 90 remitimos al Cuadro III del artículo de J. Brown y R. Salvatore, [4], págs. 439.

(37) Carta de Fl. García al H. Mayor, 9/4/1795, AGN, IX, 6.8.3. subrayado nuestro. 
en detalle la forma en que eran pagados los salarios, la ventaja que obtenía la estancia con el pago en productos y su incidencia en la rentabilidad general de la explotación. Asimismo nos permite estudiar su evolución en función de la coyuntura (coyuntura que como veremos incluye como variable fundamental la capacidad de resistencia social de los propios peones).

Pagando los salarios en productos, la estancia va a tratar de convertir a sus empleados en un mercado semi-cautivo, con el cual obtener un beneficio mercantil suplementario, lo que de hecho significa para ella reducir los costos salariales de la explotación (38).

En la política de la estancia referida a sus empleados como mercado potencial, encontramos dos etapas bien definidas. La primera de ellas es cuando el comerciante Belgrano Pérez es síndico de la Hermandad y por lo tanto se ocupa de administrar la estancia.

En este primer período, no sabemos si por desidia de la Hermandad o producto del control que ejercía el "todopoderoso» comerciante sobre las finanzas de la misma, ésta no va a sacar ningún provecho de sus trabajadores como mercado "natural». Esto no quiere decir que los peones cobraran todos sus sueldos en plata, sino que el negocio corría por cuenta personal del Síndico, quien había instalado una pulpería en la estancia, en compañía con un tal Gerónimo Silbeira a $50 \%$ de utilidades cada uno.

La Hermandad pagaba todos sus gastos en plata, pero esa plata iba directamente a Belgrano en pago de todas las mercancías que la pulpería había dado a los peones de la estancia.

Esto queda muy claro cuando, por razones que no vienen al caso, embargan en 1788 todos los bienes de Belgrano, en los cuales se incluye a la pulpería de las Vacas. El comandante de las Víboras, encargado de la tarea informa que el activo de la pulpería está constituido por 245 ps 2 rls que le deben los «peones

(38) MoRIN, [1], ha planteado esto con claridad analizando casos concretos de haciendas, en este caso mejicanas. Por ejemplo estudiando el caso de la Hacienda "San Bartolomé" a fines del XVIII, que paga solo 1/3 de los salarios en plata, señala (pág. 226) "Convirtiendo a sus empleados en carnívoros ocasionales de grado o por Tuerza, la hacienda transformaba pérdidas ciertas en ganancias seguras. También les vendía maíz y frijol al alto precio de un real el almud. Aunque fuera un establecimiento de explotación agrícola, la hacienda constituía una unidad comercial que disponía de su propia clientela interna". Más adelante (pág. 262), analizando el caso de otras 3 haciendas señala que "Estas prestaciones en especie permitían que el patrón recuperara, mediante la ganancia mercantil una parte nada despreciable del salario". 
ausentes», 301 ps 4 rls «los peones que hallaron presentes», 570 ps 4 rls de efectos que se encontraron en la pulpería y al fin 6.998 ps 5 rls «...en cuatro libramientos dados por el administrador de esta hacienda de las Niñas Huérfanas a favor del expresado Silbeira, por pagamentos y suplementos que este ha hecho a la nominada Hacienda pagaderos por Dn. Domingo Belgrano...» (quien obviamente debe eso no como individuo, sino como síndico de la Hermandad) (39).

Con lo cual todo queda "en familia». La pulpería de Belgrano y Silbeira adelanta productos a los peones por sus salarios, amén sin duda de otros productos necesarios a la estancia (para sus esclavos, etc.). Luego el administrador de la estancia (nombrado por Belgrano) otorga un «libramiento» a Silbeira por el monto debido, quien lo cobra de manos de Belgrano (con fondos de la Hermandad), obteniendo así utilidades que se dividen Silbeira y Belgrano (en este caso a título personal por supuesto).

Y estas utilidades estaban lejos de ser despreciables. Conocemos el resultado de las transacciones de esta pulpería para el período inmediatamente posterior al arresto de Belgrano. Desde principios de 1789 hasta abril del año siguiente, la Hermandad autoriza a Silbeira a continuar al frente del negocio, en este caso a $50 \%$ de utilidades entre él y la Hermandad. Cuando deciden cancelar esta compañía, se hace el balance de las operaciones y en ese año y 2 ó 3 meses, la pulpería ha vendido productos a los peones por un «principal» de 2.879 ps, a un precio de 4.239 ps. Es decir que la utilidad neta es de $1.360 \mathrm{ps,} \mathrm{con} \mathrm{un} \mathrm{benefico} \mathrm{del}$ $47 \%$ aproximado sobre los gastos (los fletes no se indican explícitamente y no sabemos si están incluidos en el "principal», en todo caso debe haber sido un $\%$ muy bajo del total invertido) (40).

Comparado con las utilidades que luego veremos de la estancia, las de la pulpería son muy elevadas (41), y aun la Hermandad desconfía que en las cuentas de ésta, confeccionadas por Silbeira,

(39) Carta de F. Albin al virrey Loreto, 7/2/1789 y 16/2/1789, AGN, IX, 30.9.9., exp. 18, subrayado nuestro.

(40) "Cuenta de la Pulpería que tubo en la estancia..." 15/4/1790, 16/8/1790, 21/8/1790, AGN, IX, 6.8.2.

(41) Esto nos hace recordar lo que Ruggiero Romano en su seminario en la Ecole des Hautes Etudes en Sciences Sociales, contaba de cuando una compañía inglesa revisa las cuentas de sus minas de salitre en Chile y la conclusión del contador en Londres es que hay que vender las minas, pero mantener la tienda de raya. Claro que lo que este contador no veía desde Londres, es que para mantener la tienda hay que mantener también las minas. 
se haya escamoteado una parte de las utilidades, ya «...que por los precios corrientes en aqa. estancia de los efectos según lo que practicamte. se ha experimentado con los que llebó el señor Hermo. Mayor deberían corresponder a 60 por ciento que han dado de utilidad en ellos, esto no havdo. en este manejo como en el de Silbeyra bebidas en las quales se save resulta maior utilidad que en los generos» (42).

A partir de entonces y probablemente al hacerse consciente la Hermandad del lucro que se puede obtener considerando a la estancia como un mercado, es que decide tomar plenamente a su cargo la entrega de productos a los peones. No sin que mediara una discusión a lo largo de 1789-90, que es interesante referir por la claridad que arroja sobre este tipo de mecanismos.

El que era en ese entonces administrador de la estancia, Florencio García, es un acérrimo opositor a la existencia de una pulpería con las características que tenía hasta ese entonces, entre otras cosas porque una de sus principales actividades era vender aguardiente a peones y esclavos, con las consiguientes «embriagueces» y "peleas» entre los mismos. En apoyo de este argumento refiere que una vez «...se me llamo saliere porque se estavan matando los peones y esclavos estimulados de la envriagues, y haviendo salido a remediar este tan conocido daño, lo pude conseguir en parte, evitando muertos, pero no heridos de cuidado, a costa de mi vida... espero se tome la mas pronta providencia a fin de extinguir enteramente tan nociva Pulperia" (43). Dice además que dicha pulpería vende a los peones a precios excesivos y por lo tanto éstos no quieren aceptar dichos productos. De cualquier manera, García es muy consciente de la necesidad de tener productos para pagar a los peones, porque sino «...me veo en la precisión de ocurrir a las Pulperías de la capilla, y comprar lo que necesitan dhos. peones, dando a estas (pulperías, JG), el veneficio que puede disfrutar esta Hacienda..." (44).

Un mes antes había dicho lo mismo en una "Representación» que elevó a la Hemandad recomendando que no se traiga bebida,

(42) Ibid. nota 40, 16/4/1790. Subrayado nuestro. Remarcamos "los precios corrientes en aqa. estancia" porque hacen pensar que estos precios no son siquiera los de "aquella Banda", sino los de un mercado cautivo o semi-cautivo, que es la estancia en particular.

(43) F. García a M. Basavilbaso, 31/1/1790, AGN, IX, 6.7.9.

(44) Subrayado nuestro, carta de id a id del $1 / 12 / 1789$, ibid. 
pero «...si ropa para los peones y demás, entregándose a su administrador para que este la distribuya y de cuenta de su producto: cuias utilidades redundaran en veneficio de la casa, y serán más soportables sus gaston (45).

Como se ve, García es plenamente conciente de que el pago en efectos permite reducir los abultados gastos salariales de la estancia, a través de las utilidades propias de ese mecanismo mercantil.

Finalmente se suprime la pulpería, a pesar de algunas voces que se oponen a ello para quitarles pretextos a los peones de ir a otras partes a satisfacer sus «vicios» (46). Pero se resuelve que la estancia asuma a su pleno beneficio la entrega de productos a los empleados. En las instrucciones para el manejo de la estancia de 1791, en su punto 4, se establece que los salarios se pagarán «...cuando los peones bajen a Missa, y en este acto tendrá especial esmero de inclinarles a que tomen a cuenta alguna ropa del Almazén de la casa...» (47).

De aquí en más todos los cálculos de rentabilidad de la estancia de las Vacas, incluyen sistemáticamente la utilidad por la entrega de efectos a los peones, que incluso a partir de 1795 se anotan en las cuentas de la estancia como un rubro más de sus ingresos (48).

Cuando la Hermandad se atrasa en mandar géneros a la estancia para los peones, es el propio administrador quien se queja «...pues de haberlos tenido (los géneros, JG) aquí con anticipazn. se huviese logrado el lucro qe. dimana de su expendio en los peones, en virtud de su venta» (49).

Cuál era concretamente el «lucro que dimana de su expendio en los peones» de estos productos?

Veamos el caso de los años 1792-94.

En esos tres años el gasto corriente de la estancia es de 14.654 ps 4 rls (ver Cuadro 3), de los cuales el 65,7\% corresponde a salarios. Pero esos salarios fueron pagados de la siguiente

(45) "Representación que hacen Dn. F. García...", 30/10/1789, AGN, IX, 6.7.9., subrayado nuestro.

(46) Esto lo plantea por ejemplo el visitador F. de Rosa en una carta del 30/6/1792, AGN, IX, 6.8.1.

(47) "Instrucciones para el ramo de la leña...", 31/7/1791, AGN, IX, 6.8.1.

(48) Ver todas las cuentas de la estancia a partir de ese año.

(49) Subrayado nuestro, F. García a T. A. Romero, 15/4/96, AGN, IX, 6.8.3. 
manera: 3.915 ps $1 \mathrm{rl}$ en plata y $5.845 \mathrm{ps} 4 \mathrm{rls}$ en productos (50), es decir un 40,1 y un 59,9\% respectivamente.

En los libros de cuenta de la estancia de estos años, como dijimos, todavía no se consigna cual es la utilidad por la entrega de esos productos a los peones, sino que el administrador los anota simplemente como gastos a los precios entregados a los mismos (51). Sin embargo conocemos a través de las mismas cuentas, los precios del "principal» de algunos de estos productos, lo que comparado con su precio a los peones da la siguiente diferencia:

CuAdro 6. UTILIDAD EN LA VENTA DE ALGUNOS PRODUCTOS A LOS PEONES. 1792-94 (en pesos y reales corrientes)

\begin{tabular}{llll}
\hline PRODUCTO & PRECIO «PRINCIPAL” & PRECIO AL PEON & \% AUMENTO \\
\hline 1 cuchillo & $1 \mathrm{real}$ & $2 \mathrm{reales}$ & 100 \\
Pocho ordinario & $1 \mathrm{ps} 2 \mathrm{rls}$ & $2 \mathrm{ps} 4 \mathrm{rls}$ & 100 \\
Jerga labrada & $3 \mathrm{ps} \mathrm{a} 3 \mathrm{ps} 4 \mathrm{rls}$ & $6 \mathrm{ps} 4 \mathrm{rls}$ & $85 \mathrm{a} 117$ \\
Freno & $4 \mathrm{rls}$ & $8 \mathrm{rls}$ & 100 \\
Lienzo lino (vara) & $43 / 4 \mathrm{rls}$ & $7 \mathrm{rls}$ & 47 \\
Camisa ponteví & $1 \mathrm{ps} 6 \mathrm{rls}$ & $2 \mathrm{ps} 4 \mathrm{rls}$ & 43 \\
Sombrero ordinario & $1 \mathrm{ps} 2 \mathrm{rls}$ & $2 \mathrm{ps} 4 \mathrm{rls}$ & 100 \\
\hline
\end{tabular}

Fuentes: AGN, IX, 6, 8,3, "Cuenta general...» y «Cuaderno de asiento

Como podemos observar en este Cuadro 6, la utilidad en la entrega de efectos a los peones en esos años parece girar alrededor del $100 \%$. Esto quiere decir que si la estancia pagó salarios en productos por 5.845 ps 4 rls, muy probablemente solo la mitad de esa cifra sea el precio "principal» de los efectos y el resto (otros 2.922 ps 6 rls) la utilidad.

Esta hipótesis a su vez la confirmamos por otra vía. Existen dos formas posibles para calcular las utilidades corrientes de la

(50) La suma de estas dos cifras es $9.760 \mathrm{ps} 5 \mathrm{rls}$, es decir un poco superior a la indicada en el Cuadro 3, ya que allí indicamos el monto salarial correspondiente a esos años, mientras que esta cifra es la realmente pagada (que incluye pago por deudas salariales del 91). Ver "cuenta general de cargo y data...", AGN, $\mathrm{IX}, 6.8 .3$.

(51) Una situación similar se plantea como hipótesis HALPERIN, sobre la contabilidad betlemita de la estancia de Fontezuela, cuyas utilidades serían mayores que las que allí aparecen por este tipo de artificio contable; [8], pág. 448. Como veremos en nuestro caso esto es verificable. 
estancia: una es considerar el conjunto de ingresos de la estancia (que incluye el producto de las ventas hechas en Buenos Aires por la Hermandad con los productos recibidos de la estancia, como el producto de las ventas realizadas directamente en la estancia [leña, carne, etc.]) menos el total de los gastos de la estancia (como indicados en el Cuadro 3). La otra forma es considerar solo los ingresos de la Hermandad por las ventas de productos de la estancia, menos los gastos hechos por la misma Hermandad para el funcionamiento de la estancia (envíos de plata y productos a la misma, pagos de fletes, etc.).

Las fuentes nos permiten hacer estos cálculos, como lo vemos en el Cuadro 7.

En ambas formas de cálculo, la utilidad, es decir la diferencia entre ingresos y gastos, debería dar una cifra absoluta igual, aunque en el primer caso siempre los ingresos y egresos son superiores y también por ello mismo el cálculo porcentual de estas utilidades sobre los gastos es siempre superior en el segundo caso (esto es así por la sencilla razón que la Hermandad no cubre todos los gastos de la estancia con lo que le envía, sino que una parte lo es hecho con el ingreso de las ventas locales, y estas últimas explican que también los ingresos en la primera forma de cálculo sean siempre superiores; asimismo en el primer caso se consigna en los gastos el precio al que se dan los productos a los peones, y en los ingresos la utilidad por ello, mientras que en el segundo caso, solo está el precio del principal en los gastos y la utilidad por supuesto no figura en los ingresos).

Como se puede observar en el Cuadro 7, para los años 1796 y 1805, la cifra absoluta de utilidad es igual en ambas formas de cálculo (52), y en el caso de 1792-94 la primera cifra es muy inferior a la segunda. ¿Por qué esa diferencia?

Como dijimos, desde 1795 en los ingresos de la estancia se contabiliza también como un rubro más, las utilidades por la entrega de productos a los peones, pero en 1792-94 esto todavía no es así, por lo tanto para conocer los ingresos reales de estos últimos años, deberíamos adicionarles esas utilidades (que desconocemos, pero calculamos cercanas a los 2.922 ps), con lo cual también las utilidades generales de la estancia en ese período se deberían aumentar en la misma cifra y así llegaríamos a 6.784 ps $1 \mathrm{rl}$ (es decir la utilidad según la primer forma de cálculo del

(52) En realidad hay una pequeña diferencia que se debe explicar por algunos gastos (fletes sin duda) que se anotan en algunos casos sí y otros no, o por errores en las anotaciones contables. 


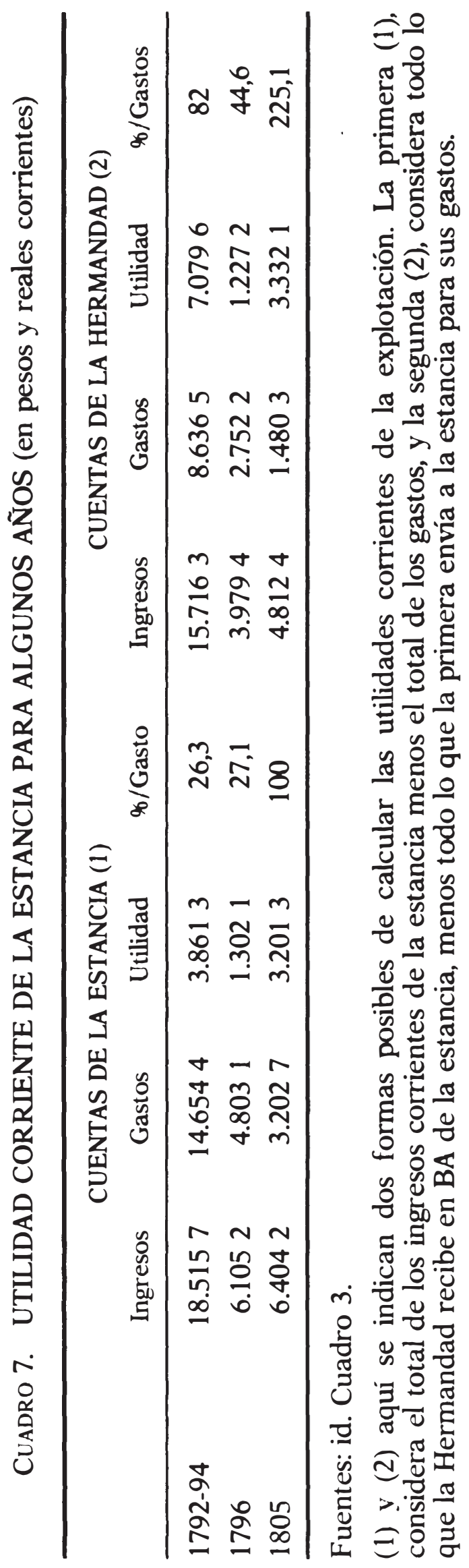

R. I., 1992, n으 195/196 
Cuadro 7, 3.861 ps 3 rls +2.922 ps 6 rls), ahora sí una cifra muy cercana a la utilidad obtenida según la segunda forma de cálculo del Cuadro 7.

Esto entonces nos confirma que el cálculo que hicimos anteriormente, de utilidad por la entrega de efectos a los peones en esos años 92-94 es bastante cercano a lo que debió ser en realidad.

Y estas cifras nos permiten a su vez medir la magnitud que podía llegar a tener la aplicación de este mecanismo mercantil en la rentabilidad general de la explotación.

Si la estancia en esos años tuvo un gasto salarial nominal de 9.760 ps 5 rls, al haber logrado pagar un 59,9\% en productos, con una utilidad cercana al 100\%, de hecho logró reducir el gasto salarial total en un $30 \%$ (en vez de gastar esos 9.760 ps 5 rls, gasto eso menos los 2.922 ps que cargó a los precios de los productos entregados a los peones).

$O$ si se quiere expresar de manera aún más significativa, podemos decir que si la utilidad real de la estancia en esos años fue cercana a los 7.000 ps, más del $40 \%$ de esa cifra está compuesta por la sola utilidad de la venta de efectos a los peones, o aún más impresionante: la utilidad sin la aplicación de ese mecanismo mercantil ( 3.861 ps 3 rls), se vio aumentada en un $75 \%$ $(2.922 / 3.861)$ por ello.

Creemos que estas cifras son claramente ilustrativas del rol del capital mercantil en esta sociedad, y de como utilizando este tipo de mecanismos se puede obtener una parte sustancial del excedente social.

Por supuesto no todos estaban en condiciones de convertirse en comerciantes o aplicar algunos de estos mecanismos mercantiles. Esto dependía por un lado del poder económico-político de la persona o grupo, de las características de los mercados regionales y de las relaciones sociales (más o menos libres o coactivas), así como de la evolución de la coyuntura.

Ya mencionamos el caso de los pequeños «labradores» rioplatenses, quienes lejos de aprovechar a su favor las características de los mercados y los mecanismos propios del capital comercial, eran expoliados por los comerciantes que les adelantaban productos a precios inflados o plata a cambio de sus cosechas a bajos precios. Estos labradores no tenían por lo general acceso a los mercados más importantes y si lo tenían se veían obligados a vender su producción en los momentos de mayor oferta estacional y precios más bajos (es decir inmediatamente después de la 
cosecha), así como a aumentar la oferta al mercado a través de la liquidación de sus pequeñas tropillas de animales en las coyunturas de bajos precios (como vimos que también tuvo que hacer la estancia de las Vacas en 1797).

En el polo opuesto de estos se encuentran personajes como Belgrano Pérez o en cierta medida la Hermandad de la Caridad, que pueden intentar aprovechar esas circunstancias a su favor.

Tienen capital suficiente (en el caso de Belgrano) para soportar las malas coyunturas de precios, tienen acceso a los principales mercados como para vender las producciones de sus estancias a mejores precios, así como comprar en mejores términos los insumos que necesitan, y sobre todo su posición les permite aplicar en el interior de sus propiedades los mecanismos que hemos estado describiendo sobre una clientela «natural», basados en la falta de mercados alternativos, la falta de crédito o la escasez monetaria, cuando no en la coacción.

Claro que como decíamos antes, esto depende de las características de los mercados regionales y de las relaciones sociales en un área determinada.

Los precios y condiciones de compra y venta que logra imponer un corregidor a los indígenas de su distrito están determinados esencialmente por la relación de fuerza que ejerce el primero sobre los segundos, así como por la falta de alternativas mercantiles (reales o impuestas por el propio corregidor) para esos indígenas que solo deben o pueden comprar y vender a ese corregidor.

Estos términos de intercambio deben ser más favorables para los peones de una estancia rioplatense, quienes tienen la libertad de elección de donde trabajar y residir, aunque no tanto como veremos de comprar. Y por supuesto ambos casos son diferentes de las condiciones en un mercado de una gran ciudad, donde las relaciones coactivas son más tenues y funcionan más realmente las alternativas de compra y venta.

Es ilustrativo referir al respecto, una discusión que se desarrolla en 1799 entre la Hermandad de la Caridad y el todavía administrador de la estancia, Florencio García.

La Hermandad se queja al administrador de que en esos últimos años los peones toman pocos productos, y aun de que los precios a que se los dan no dejan grandes utilidades, y aclara el Hermano Mayor que «En toda estancia hacen esto mismo y con más ventajas puesto qe. a los géneros cargan sobre el pral. 45 y 50 por ciento según me hallo vien infomado y en los qe. vm. 
da vendidos dejan la utilidad de 33 por ciento: Esta utilidad hace qe. los salarios de peones sean más equitatibos, y por esto es qe. vm. debe trabajar con arte y modo a fin de que la mitad de dhos. salarios lo menos reciban en géneros...» (53).

Tenemos en esta carta algunos elementos muy interesantes: por un lado la referencia de que el mecanismo que hemos descrito para pago de salarios no era exclusivo de la estancia de las Vacas, sino de "toda estancia", con el objetivo de que dichos salarios sean "más equitatibos» (para el propietario por supuesto): pero también es interesante notar que esto no es un derecho adquirido por la estancia, ni por ley, ni por fuerza, sino que el administrador debe trabajar "con arte y modo" para lograr ese fin. Y esto último se aclara aún más con la respuesta que da el administrador Fl. García. Dice que u...los peones no están conchabados a pagarles en géneros sino buenamte. proponerles para qe. puedan llebarlos el qe. los quiera...", y se queja que "...los más de ellos no quieren sino dinerom. Luego explica que la utilidad del $33 \%$ en la venta de los efectos a los peones es muy razonable, sobre todo siendo tiempos de guerra (europea) porque «....aora se queda esta (la utilidad, JG) pa. los negociantes, y no pongo duda se bendan con estas bentajas (45 ó $50 \%$, JG) en parages mui remotos qe. no haiga otros qe. bendan con más equidad, pero en esta (Banda, JG) donde estoy cercado de mercaderes por todas partes y qe. estos benden sus géneros mucho más barato..." (54).

A pesar de la mala escritura, el razonamiento del administrador es magnífico! Es plenamente conciente de cuales son los factores que están condicionando la posibilidad de pagar a los peones en géneros y a precios muy inflados: uno de ellos es la coyuntura a la que nos referiremos luego y el otro son las características de los mercados locales y de la relación con los peones. Se puede presionar a los peones a comprar productos a ciertos precios, pero hasta un cierto límite, ya que sino tienen la alternativa de ir a comprarlos a otros mercaderes en mejores condiciones. Y en esto juegan tanto la relativa libertad del peón, como la existencia en la campaña de la Banda Oriental de una multitud de pulperías estables o volantes que disputaban la clientela a los grandes hacendados.

Conocemos la existencia de las primeras, instaladas sobre todo por los grandes propietarios en sus explotaciones o en los

(53) Carta del 5/8/99, AGN, IX, 6.8.5.

(54) Carta de F. García al H. Mayor, 27/8/1799, AGN, IX, 6.8.5., subrayado nuestro. 
pueblos de la campaña, así como de las pulperías más o menos volantes, muy ligadas a su vez al contrabando de cueros (55).

Los hacendados se quejan asiduamente de estas últimas y promueven la persecución de esos mercachifles, tanto porque ofrecen una alternativa mercantil a los peones y habitantes de la campaña para sus compras, así como estimulan el robo de ganados, cuyos cueros son comprados por estos vendedores ambulantes, haciéndolos circular por circuitos no muy legales.

En una ocasión el comerciante y también estanciero en la Banda Oriental, Miguel de Azcuénaga, junto al también estanciero y Hermano Mayor de la Caridad, Tomás Antonio Romero, presenta un escrito a las autoridades de Colonia, Víboras y Santo Domingo Soriano, quejándose por una importante extracción ilegal de cueros de ganado alzado y explican que «...se han partido este tesoro inmenso (el ganado alzado, JG) entre los portugueses, los ladrones y los mercachifles que dominan aquellos terrenos por las pulperias que tienen repartidas a proporcionadas distancias a pretexto de abastos..." (56).

Obviamente estos estancieros no explican que también les perjudican porque les quitan clientela a sus propias pulperías o más bien les obligan a bajar sus precios, pero como hemos visto por la correspondencia privada de la estancia de las Vacas, este tema les preocupa casi hasta la obsesión.

Por último, la capacidad para un gran estanciero-comerciante de aplicar con más o menos éxito los mecanismos mercantiles que describimos, depende también de la evolución de la coyuntura, dentro de cuyos elementos aparece como fundamental la evolución del poder negociador o de resistencia de los trabajadores sobre los cuales se pretende aplicar esos mecanismos. Ya tuvimos una referencia sobre ello en la carta del administrador de 1799, donde explica que es más difícil pagar en productos y a precios inflados por ser tiempos de guerra.

En la estancia de las Vacas podemos ver a lo largo de los años una enorme variación en la forma de pago de los salarios, tanto en la proporción de géneros que se pueden dar como parte de pago, como en el porcentaje que se puede aumentar sobre el precio «principal» de esos productos.

(55) Ver L. Sala y otros, Estructura económica de la colonia, Ed. Pueblos Unidos, Montevideo, 1968, págs. 38-39; A.J. MonToYA, Como evolucionó la ganadería en la época del virreinato, Plus Ultra, BA, 1984, págs. 134.

(56) Informe del 15/1/1796, AGN, IX, 6.8.3. 
CuAdro 8. SALARIO EN PLATA Y EN PRODUCTOS A LOS EMPLEAdOS DE LA ESTANCIA (en ps y rls corrientes)

\begin{tabular}{lllccc}
\hline & PLATA & $\%$ & PRODUCTOS & $\%$ & TOTAL \\
\hline $1792-94$ & 3.9151 & 40,1 & 5.8454 & 59,9 & $9.7605(1)$ \\
1795 & 2.626 & 63 & 1.543 & 37 & 4.169 \\
1796 & 2.9444 & 75,8 & 9386 & 24,2 & 3.8833 \\
1797 & 5.7392 & 92,8 & 445 & 7,2 & 6.1842 \\
1798 & 4.6402 & 89,5 & 5413 & 10,5 & 5.1815 \\
1799 & 1.7182 & 61,2 & 1.0914 & 38,8 & 2.8096 \\
1805 & 1.586 & 83,7 & 3083 & 16,3 & $1.8943(2)$ \\
\hline
\end{tabular}

Fuentes: AGN, IX, 6.8.3., 6.8.7., 37.5.4. (exp. 14, 15 y 17), 31.7.2. (exp. 1053), 31.7.4. (exp. 1115), 31.7.5. (exp. 1141), 31.7.6. (exp. 1178).

(1) La diferencia de esta cifra con el total salarial de esos años en el Cuadro 3, es porque en el 8 hemos indicado el total salarial pagado efectivamente, mientras que en el otro hemos indicado el total salarial correspondiente a esos años (descontando los pagos de deudas salariales de otros años y sumando los salarios auú no pagados, pero correspondientes a estos años.

(2) En este caso la diferencia con el total salarial del Cuadro 3, se debe a que en este Cuadro 8 no se incluyen los salarios a montaraces y otros como carpintero, herrero y jabonero por desconocer la forma en que se pagó.

En el Cuadro 8 podemos observar, sobre un total de 9 años para los cuales conocemos en detalle la forma de pago salarial, que el porcentaje en efectos varía desde un mínimo de 7,2 \% en 1797 hasta el máximo de $60 \%$ en los años 92-94.

De la misma manera en el Cuadro 9 (columnas D y E) podemos observar que el por ciento de aumento de los precios de esos productos sobre el principal varía enormemente coincidiendo en principio, para los años que conocemos, la baja en este rubro con la baja en el anterior.

Por supuesto que la incidencia combinada de estos dos elementos, hace que también varíe mucho a lo largo de los años el beneficio que el propietario puede obtener con la aplicación de este mecanismo. Obviamente este beneficio será mayor cuanto mayor sea el porcentaje de pago en productos y de aumento de los precios (columnas $\mathrm{G}$ y $\mathrm{H}$ del Cuadro 9).

¿Cómo explicar estas variaciones a lo largo de los años?

Sin duda en ello incide tanto la evolución de la conveniencia para el propietario de pagar en plata o en efectos, como la posibilidad de hacerlo.

Si observamos nuevamente los Cuadros 8 y 9 , podemos en principio hacer un corte en dos entre los años de la década del 


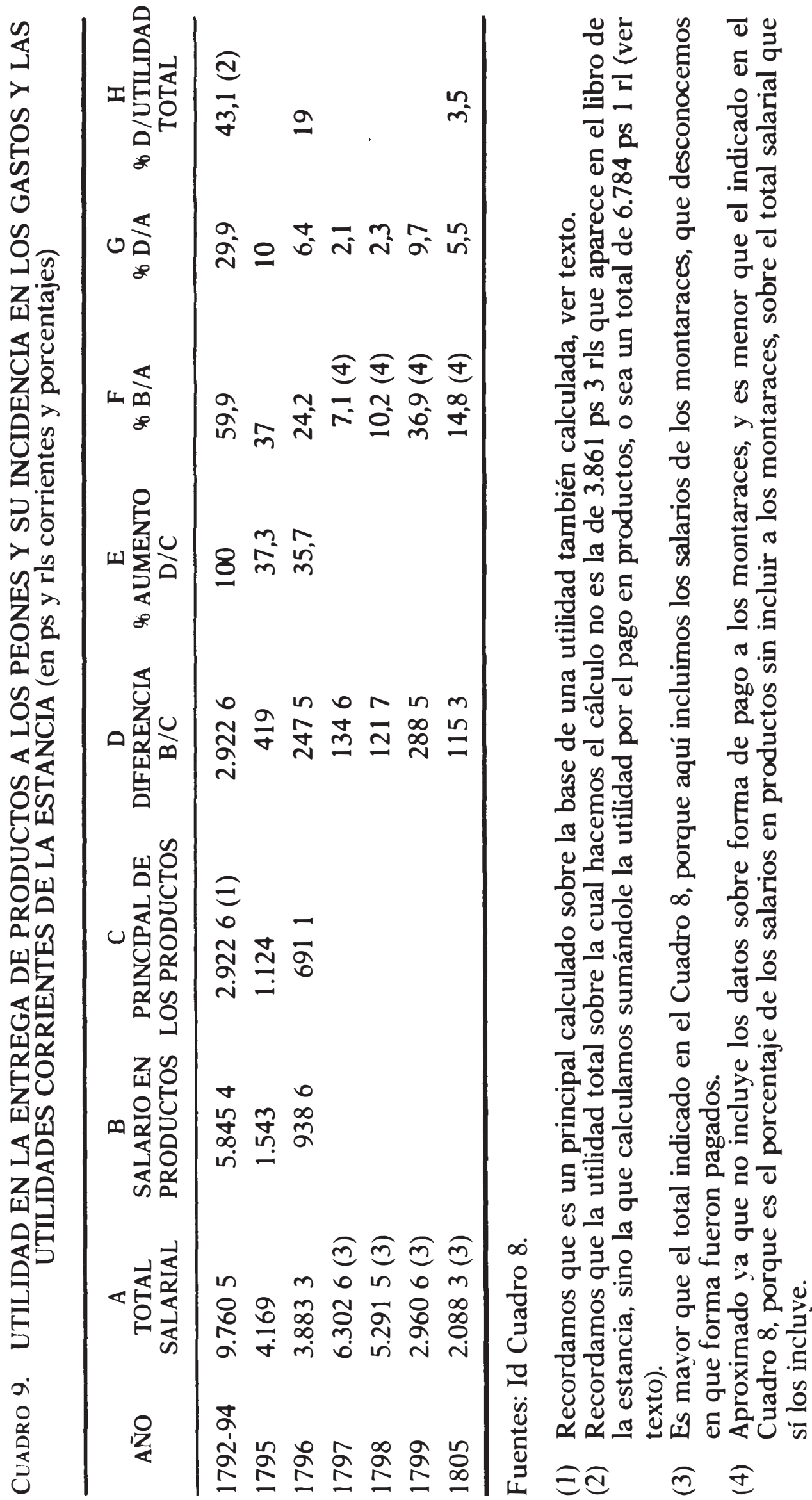

R. I., 1992, 쓰 195/196 
90: este corte se ubicaría muy claramente entre los años 92-94 y 96-99, donde 1795 parece un punto de transición (57).

Y sin duda uno de los elementos que produce este corte es el inicio de la guerra europea en 1796, que tiene como efecto casi inmediato cambiar en muchos aspectos la coyuntura comercial y de precios (58). Cae el comercio atlántico y con él caen en el Río de la Plata los precios de los productos de exportación como el cuero, encareciéndose los productos importados, y como efecto de arrastre, también los de otros productos americanos que pueden reemplazar en cierta medida a los importados (ciertos tejidos, vino, etc.).

Esto se combina con una mayor existencia local de moneda metálica que ya no puede salir fácilmente hacia Europa (59).

En resumen encontramos una coyuntura que hace que al propietario no le sea tan conveniente pagar los salarios en productos y le sea quizás más fácil hacerlo con plata.

Como lo explicaba en la carta ya citada el administrador, en 1799, en estos tiempos de guerra la utilidad queda para «los negociantes" que cobran las mercancías a precios muy inflados (60), y la estancia no puede aumentar esos precios como en otras épocas a los peones. Ya en 1797, Florencio García le pide a la Hermandad que no le mande tantos productos porque allí en Buenos Aires están muy caros (61).

A su vez un elemento fundamental de la evolución de la coyuntura, que en este caso condiciona la posibilidad de la estancia de aplicar ese tipo de mecanismo, es la evolución de la capacidad de resistencia o el poder negociador de los trabajadores de la campaña.

Estamos muy acostumbrados a considerar las sociedades pa-

(57) Aclaramos que el hecho que en los años 92-94 aparezca un alto porcentaje de pago en productos a precios muy inflados, no corresponde a que esto haya sido para uno solo de esos años, lo cual inflaría las cifras para los 3 al considerarlos de conjunto. Estuvimos obligados a indicarlos así (los 3 juntos) porque desconocemos el detalle en la forma de pago año a año, para todos los niveles ocupacionales de la estancia. De todos modos conocemos, sí, las formas de pago año a año por lo menos para los peones de los puestos y los porcentajes de pago en productos a los mismos son: $70,5 \%$ en $1792,57,9 \%$ en 1793 y $64,9 \%$ en 1794, con lo cual se confirma que los niveles fueron igualmente altos en los tres años ("Cuenta general...", AGN, IX, 6.8.3.).

(58) Ver los trabajos citados en nota 19, para ver la caída del comercio.

(59) Al estudiar las actividades de Belgrano como comerciante, encontramos que en los años de guerra europea (en ese caso 1780-82), una de sus principales actividades pasa a ser los préstamos monetarios en el interior de América.

(60) Carta del 27/8/99, AGN, IX, 6.8.5.

(61) Carta del 27/4/97, AGN, IX, 6.8.4. 
sadas como estructuras todopoderosas, casi inmóviles, que definen el accionar de todas sus partes y gentes, y a restar importancia a las actitudes positivas de los actores sociales que pueden incidir y aún modificar esas estructuras en parte o completamente. Y aún cuando se toma en cuenta las actitudes de los grupos o personas, se tiende a hacerlo solo con los grupos dominantes, siendo los "dominados" meros receptores de la explotación y de las disposiciones de los «mandantes» (62). Solo en los últimos años se ha comenzado a reconsiderar aspectos de la vida colonial americana y en particular de su vida rural, tomando en consideración que allí hay conflictos sociales constantes y que los trabajadores no eran víctimas inmóviles, sino que sabían aprovechar sus posibilidades de resistencia (63).

Y lo que pasa en la estancia de las Vacas con los salarios, es un excelente ejemplo de ello.

La guerra parece haber incidido en una mayor escasez relativa de mano de obra. En 1797 el Administrador pide urgente que le manden de Buenos Aires 10 o 12 upeones de campo con los aperos necesarios qe. me están haciendo mucha falta pues con el motibo de la guerra por acá están muy escasos...» (64). En el caso específico de la estancia de las Vacas, esta situación se agrava considerablemente, ya que como vimos su primer reacción frente a la caída del precio local del cuero por la guerra, es decidir aumentar el faenamiento de ganado y la venta de cueros para mantener un nivel de ingresos elevado. Entonces en estos años de 1797 y 98 se combinan para la estancia de las Vacas una caída de la oferta de mano de obra, con un aumento de su demanda de trabajo, lo que la coloca en una muy mala posición frente a los peones. Sin duda que esto explica en gran medida

(62) Incluso en un excelente libro como el de C. Morin (opp. cit., págs. 268), cuando habla del fenómeno del endeudamiento de los peones y del pago salarial en productos, señala "El patrón fija el volumen del crédito de la misma manera en que determina el ritmo de los gastos". Como se ve aquí la imagen que se presenta es la de un trabajador que no tiene más alternativa que aceptar las condiciones que le impone su patrón.

(63) Ver referencias a este tipo de estudios y problemas en A. J. BAUER "Rural Workers in Spanish America: Problems of Peonage and Oppression", HAHR, 59:1, 1979, págs. 38 y 41; así como E. VAN Young "Mexican Rural History since Chevalier: the Historiography of the Colonial Hacienda", LARR, XVIII, 3, 1983, págs. 5-61.

(64) Carta del 18/6/97, AGN, IX, 6.8.4. No entraremos a analizar aquí los motivos de esta escasez con la guerra, pero puede estar influido por el reclutamiento de milicias locales para cuidar las fronteras o reemplazar a las tropas profesionales en esás u otras tareas, así como por eventuales alternativas laborales que se abren a los habitantes de la campaña en época de guerra. 
que de todos los años indicados en los Cuadros 8 y 9 , estos dos son aquellos en que la estancia paga el menor porcentaje de salarios en productos, combinado con un muy bajo incremento en su precio a los peones. En estos dos años las utilidades por la entrega de productos a los peones apenas representa un 2,1 y un 2,3\% respectivamente del gasto salarial total (columna $G$ del Cuadro 9).

Una clara prueba de que el poder negociador de los trabajadores incide en la forma de pago del salario, nos la da la diferencia en ello entre las diversas categorías de trabajadores en cada año.

CUADRO 10. FORMAS SALARIALES SEGUN OCUPACION O CATEGORIA DE EMPLEO (en ps y rls corrientes)

\begin{tabular}{|c|c|c|c|c|c|}
\hline AÑO & OCUPACION & PLATA & 9 & PRODUCTOS & $\%$ \\
\hline \multirow[t]{2}{*}{$1792-94$} & $\begin{array}{l}\text { administrador, ayud., capellán } \\
\text { cosecheros } \\
\text { garandumba } \\
\text { montaraces } \\
\text { peones }\end{array}$ & $\begin{aligned} 5416 \\
1832 \\
666 \\
2642 \\
2.8591\end{aligned}$ & $\begin{array}{l}92,6 \\
87 \\
62,9 \\
38,4 \\
35\end{array}$ & $\begin{array}{rl}43 & 3 \\
27 & 3 \\
39 & 1 \\
4242 \\
5.3113\end{array}$ & $\begin{array}{l}7,4 \\
13 \\
37,1 \\
61,6 \\
65\end{array}$ \\
\hline & TOTAL & 3.9151 & 40,1 & 5.8454 & 59,9 \\
\hline 1796 & $\begin{array}{l}\text { administrador, etc. } \\
\text { capataces puestos } \\
\text { carreteros } \\
\text { cosecheros } \\
\text { cuereadores extraordinarios } \\
\text { peones puestos } \\
\text { montaraces (*) } \\
\text { TOTAL }\end{array}$ & $\begin{array}{c}1095 \\
5323 \\
3442 \\
497 \\
206 \\
1.574 \\
1282 \\
2.9444\end{array}$ & $\begin{array}{l}86,5 \\
82 \\
75,4 \\
100 \\
100 \\
73,4 \\
51 \\
75,8\end{array}$ & $\begin{array}{r}17 \\
1171 \\
1124 \\
- \\
5693 \\
1226 \\
9386\end{array}$ & $\begin{array}{l}13,5 \\
18 \\
24,5 \\
7 \\
25,6 \\
49 \\
24,2\end{array}$ \\
\hline \multirow[t]{2}{*}{1799} & $\begin{array}{l}\text { administrador, etc. } \\
\text { capataces puestos, carpintero } \\
\text { cosecheros } \\
\text { peones gral. }\end{array}$ & $\begin{array}{r}220 \\
1695 \\
104 \\
1.3181\end{array}$ & $\begin{array}{r}100 \\
66 \\
100 \\
57,8\end{array}$ & $\begin{array}{r}87 \overline{3} \\
1.004 \overline{1}\end{array}$ & $3 \overline{4}$ \\
\hline & TOTAL & 1.7182 & 61,2 & 1.0914 & 38,8 \\
\hline \multirow[t]{2}{*}{1805} & $\begin{array}{l}\text { administrador, etc. } \\
\text { capataces puestos } \\
\text { peones gral. }\end{array}$ & $\begin{array}{l}2746 \\
4414 \\
8696\end{array}$ & $\begin{array}{l}99,7 \\
94,7 \\
75,5\end{array}$ & $\begin{array}{r}4 \\
246 \\
2831\end{array}$ & $\begin{array}{r}0,3 \\
5,3 \\
24,5\end{array}$ \\
\hline & TOTAL & 1.586 & 83,7 & 3083 & 16,3 \\
\hline
\end{tabular}

Fuentes: id. Cuadro 8.

(") Estas cifras para los montaraces son calculadas a partir de las cif ras globales salariales en plata y productos, ya que en la contabilidad es el único caso en que no está detallada la forma de pago. 
Como se puede observar en el Cuadro 10, donde indicamos los porcentajes de pago en plata y productos para varios años, para los distintos tipos de empleados, las diferencias entre estas categorías u ocupaciones pueden ser muy importantes dentro de un mismo año.

Sistemáticamente aquellos que obtienen mayor porcentaje de plata son quienes tienen mayor poder negociador: por un lado obviamente el personal jerárquico o más especializado de la estancia (administrador, capellán, capataces, marineros de la garandumba) y por el otro aquellos trabajadores que realizan algunas tareas muy específicas en un momento en que son muy demandados y en que la oferta laboral para ello es escasa. Esto sucede así sistemáticamente con los peones cosechadores del trigo (65), así como también lo observamos en 1796 cuando se contrata una partida de "cuereadores extraordinarios".

Por el otro lado los peones de los puestos, o los montaraces son quienes sistemáticamente reciben un menor porcentaje salarial en plata (66).

El caso de los peones cosecheros es muy ilustrativo: estos reciben salarios nominales que duplican el del peón ganadero (4 rls por día contra 7 ps por mes respectivamente) y como se ve en el Cuadro 10 reciben el $100 \%$ en plata casi siempre.

Los trabajadores de la estancia parecen ser conscientes del perjuicio que se les causa con el pago en productos y tratan de resistirse a ello.

Tenemos múltiples referencias sobre esto en la correspondencia de los administradores con la Hermandad; citaremos algunos ejemplos:

- El 26/11/1792 el administrador Posadas escribe hablando de las bondades de la venta de leña porque «...este es el único ramo qe. sostiene el pago de Peones, o nos da algún dinero para dárselos efectibo porque a los efectos le tuersen un poco el rostro.... (67).

(65) Las fuentes de la estancia de las Vacas atestiguan fehacientemente la escasez de brazos en época de cosecha. En el Cuadro 5, se observa que sistemáticamente a fines de diciembre, enero y febrero es cuando la estancia tiene menos peones. Y los administradores lo explican repetidamente. Para citar un solo ejemplo, en noviembre de 1800, el administrador F. Wright dice "...y me han asegurado qe. desde fines de Dre. hasta Marzo queda la casa con solo los esclavos (por la siega, JG)...", carta del 6/11/800, AGN, IX, 6.8.5. y sig.

(66) Un caso similar encontraron GLAVE y REMY para el Perú, [12], págs. 360

(67) AGN, IX, 6.8.2., subrayado nuestro. 
- El mismo, explica el 31/10/93 «Me he visto aquí en los mayores apuros que se pueda ver con esta indomita gente para sus pagos de lo que tienen bensido pues todos solisitaban su pago en dinero efectibo y me presiso el desirles que se conformasen a mitad plata y lo demás en efectos a lo que se negaban.... (68).

- El 5/11/95, el nuevo administrador Fl. García solicita dinero a la Hermandad «...pues me hallo hace tiempo sin él, y por consiguiente debiendo a la gente, la que exige pa. el cobro de sus salarios...." (69).

- y un último ejemplo, este mismo el $31 / 1 / 95$, explica que tiene pocos peones «...y los qe. estaban antes se han ydo pr. qe. no ai plata pa. pagarlos, y estos no quieren ropa..." (70).

Y a pesar de esto, como hemos visto, la capacidad de los peones de tener éxito en su resistencia al pago en efectos no era siempre igual. Al analizar los Cuadros 8 y 9 señalamos que parecen tener más éxito después del inicio de la guerra europea en el 96 (por la combinación de su mayor poder negociador por la escasez de brazos frente a la demanda laboral en alza de la estancia, con una mejor disposición de la Hermandad a pagar en plata por la carestía de los productos y la abundancia relativa del metálico).

También vimos el caso de los cosecheros y es interesante señalar que en muchos casos éstos son peones de los puestos que se transforman en cosecheros en enero y conscientes de su temporario poder de negociación exigen su pago en plata, mientras se ven obligados a aceptar el salario mixto a lo largo del año.

Y aún un último caso que podemos señalar en que los peones adquieren conciencia de su mayor poder negociador frente a la estancia, es cuando se produce un cierto caos organizativo de la propiedad, causado por un cambio de administrador o por conflictos entre los directivos de la explotación.

Esto sucede cuando la Hermandad decide a fines del siglo, no renovar más el contrato al plurianual administrador Fl. García, y se abre una disputa entre este último y la Hermandad que genera una situación de fragilidad para la estancia. El visitador y administrador interino de la estancia, J. Posadas, explica que tiene dificultades en reclutar peones a pesar «...que respecto de

(68) Ibid. subrayado nuestro.

(69) AGN, IX, 6.8.3., subrayado nuestro.

(70) Ibid. subrayado nuestro. 
haverse acavado las ciegas se habrá ya vencido, qe. hera el obstáculo pa. los peones, es muy cierto qe. con esta esperanza estábamos, pero estos reveldes no han querido presentarse ni aún venir a esta estancia solo si preguntan si ha venido plata pa. pagarles, y saviendo qe. no no han querido venir...) (71).

Como se ve, una verdadera huelga en la campaña rioplatense del XVIII!

En resumen en este ejemplo sobre las formas de circulación en la campaña rioplatense, hemos podido estudiar en detalle algunos mecanismos del capital comercial.

Lo que sucede en la estancia de las Vacas es bastante ilustrativo sobre el rol dominante del comercio y los comerciantes en la sociedad colonial americana, que logra quedarse con una parte sustancial del excedente producido por la sociedad.

Los productores de la campaña aparecen en una posición bastante frágil frente al capital mercantil. En particular los pequeños campesinos que no tienen acceso directo a los grandes mercados, que carecen de dinero y crédito, que se ven obligados a vender y comprar productos a algunos mercaderes locales, y esto en general en los peores momentos para ellos (tanto estacionales como coyunturales).

Incluso medianos y grandes propietarios de la campaña se ven obligados a ceder una parte importante de los beneficios de la explotación a manos de estos comerciantes, como lo hemos visto en el propio caso de la estancia de las Vacas, cuando la pulpería estaba en manos de Belgrano.

Pero los grandes propietarios, pueden en determinadas condiciones aprovechar a su favor las características de los mercados coloniales, utilizando algunos de los mecanismos que estos posibilitan.

Pueden mejorar en parte su posición frente al mercado, a través del acceso directo a aquellos en los cuales se encuentren los mejores precios para sus productos. Sin embargo la evolución de los precios para su producción escapa totalmente al control de los productores, con lo cual también se convierte en aleatorio el nivel de ingresos de una estancia por este rubro.

Por el contrario es más manejable para la estancia lo que sucede en el interior de su propiedad. Un arma notable que puede utilizar el gran estanciero para mejorar la rentabilidad de

(71) Carta del 9/3/1800, AGN, IX, 6.8.5. 
su explotación, es la de considerar a sus peones no solo como trabajadores sino como clientes. En este caso concreto transformando el pago de salarios en una venta de productos en condiciones muy favorables para la estancia.

Pero el ejemplo de la estancia de las Vacas permite ver una multiplicidad de factores que condicionan la posibilidad de aplicación con más o menos éxito de este mecanismo.

Algunas de estas son estructurales y están referidas por ejemplo, a las características de los mercados locales (con más o menos transparencia y competitividad) y de las relaciones sociales (más o menos libertad de los trabajadores en sus posibilidades de elección). Pero a su vez estas condiciones pueden variar con la coyuntura y en particular con la mayor o menor resistencia que puedan ofrecer quienes son objeto de la doble explotación laboral-mercantil, los trabajadores rurales.

Como hemos visto el pago en efectos es muy variable a lo largo de los años y un elemento esencial en ello es la resistencia que oponen los peones, que en ciertas coyunturas (estacionales o casuales: guerras, crisis de administración de la estancia, etc.) pueden obtener condiciones menos desfavorables.

De cualquier manera queda como conclusión general que las condiciones de los mercados coloniales y de las relaciones sociales, ponen en situación de ventaja al comercio sobre la producción, y que las posibilidades de éxito están de parte de quien controle lo primero más que lo segundo, aunque a veces sea necesario controlar lo segundo para hacer lo primero. 